\title{
Teatro, comunicação, pedagogia: notas sobre Brecht
}

Celso Frederico

Professor da Escola de Comunicações e Artes, da Universidade de São Paulo, e bolsista do CNPq.

E-mail: celsof@usp.br

Resumo: A consequência imediata da Revolução Russa sobre os intelectuais alemães foi, na República de Weimar (1919-1933), a politização da arte. Nesse clima, Brecht aproximasse do teatro político de Piscator e escreve as peças didáticas. Daí para a frente, a trajetória de Brecht é marcada pela busca de uma comunicação interativa e pela defesa da função pedagógica da arte. As reflexões sobre o papel da arte são contemporâneas da teoria do rádio, do florescimento da imprensa operária e dos experimentos cinematográficos. É nesse quadro geral que se pode entender as propostas teatrais de Brecht.

Palavras-chaves: República de Weimar, Piscator, teatro político, comunicação, interatividade.
Abstract: The immediate consequence of Russian Revolution on German intellectuals in Weimar Republic (1919-1933) was the politicization of art. In this climate, Brecht approaches to the political theater of $\mathrm{Pi}$ castor and writes didactic plays. Thereafter, the trajectory of Brecht is marked by the pursuit of an interactive communication and by the defense of pedagogical function of art. The reflections on the role of art are contemporary to the radio theory, the emerging of labour press and the cinematographic experiments. It is within this general framework we can understand Brecht's theatrical proposals.

Keywords: Weimar Republic, Picastor, political theater, communication, interactivity.

As preocupações políticas de Brecht levaram-no à busca de uma incansável reflexão visando revolucionar a forma da representação teatral para, através da interação com o público, poder exercer a função pedagógica que ele reservava à arte. Romper a passividade, a posição meramente contemplativa do público, é o objetivo que o acompanhou por toda a vida.

A caminhada inicia-se com a sua transferência para Berlim em 1924, momento em que começa a participar do teatro político de Erwin Piscator e escreve as peças didáticas.

Poucos anos depois, ele escreve os proféticos textos que compõem a Teoria do rádio, uma reflexão pioneira sobre as possibilidades desse meio de comunicação que, naqueles tempos, era ainda uma novidade. Nesses escritos, Brecht, lembrando que o rádio surgiu como um substituto do telégrafo - portanto, para facilitar a interação entre os homens -, constata que sua utilização comercial 
1. O principal texto da Teoria do rádio encontra-se traduzido na revista Estudos Avançados: BRECHT, Bertolt. O rádio como aparato de comunicação. Discurso sobre a função do rádio. Estud. av. [on-line]. 2007, vol. 21, n. 60 , p. 227-232. ISSN 0103-4014. Disponível em: <http://www. scielo.br/pdf/ea/v21n60/ a18v2160.pdf>. No mesmo número, para consultar mais detidamente as ideias brechtianas, ver: FREDERICO, Celso Brecht e a "Teoria do rádio". Estud. av. [on-line]. 2007, vol. 21 , n. 60 , pp. 217-226. ISSN 0103-4014. Disponível em: <http:// www.scielo.br/pdf/ea/ v21n60/a17v2160.pdf>. nicação em mero aparelho de emissão e todos nós, em ouvintes. Tal modificação não se deve a razões técnicas, já que uma simples adaptação transformaria o aparelho de rádio num instrumento que, ao mesmo tempo, recebe e transmite mensagens. O potencial mobilizador e revolucionário do rádio foi fraudado, já que suas possibilidades técnicas ficaram atrofiadas. Os monopólios, assim, estabeleceram o comércio acústico e condenaram os ouvintes à passividade. As ideias de Brecht, contudo, permaneceram vivas: todo o futuro movimento das rádios liures ou rádios piratas, ao reivindicarem a reforma agrária no ar, deram continuidade aos seus ensinamentos ${ }^{1}$.

Foi também nesse período que Brecht, mais uma vez pioneiro, vislumbrou as possibilidades revolucionárias da linguagem cinematográfica e a necessidade de sua utilização no processo de educação da classe operária. Juntamente com Eisler, Ottwald e Dudow, produziu o filme Kuhle Wampe, em que explorou as possibilidades técnicas desse meio de comunicação.

A produção de Brecht reflete a efervescência política e cultural vivida na República de Weimar, contemporânea à nova etapa inaugurada pela Revolução Russa de 1917. Para se compreender esse momento em que Brecht se lançou a tantas iniciativas, é preciso entender o que se passava na área cultural da Rússia revolucionária, já que sua repercussão mobilizou a intelectualidade progressista da Alemanha. Nos dois países, a intensa fermentação cultural discutia o esgotamento das formas tradicionais de se fazer arte.

\section{A ATIVIDADE CULTURAL NA RÚSSIA PÓS-REVOLUCIONÁRIA}

Os historiadores costumam apontar três tendências que dividiram o coração e a mente dos criadores culturais russos: a proletkult, as vanguardas estéticas e a posição oficial do regime soviético que, inicialmente, defendia a tese da arte como herança cultural da humanidade e, a partir de 1934, proclamou o realismo socialista como modelo a ser seguido. Essas concepções relacionam a arte com conteúdos distintos: expressão ideológica (proletkult), técnica dotada de utilidade social (vanguardas) e momento do processo de humanização (a posição oficial do governo revolucionário, nos tempos em que Lunacharski era o encarregado da cultura). Assim, a arte tinha como referência última, respectivamente, as classes sociais, o desenvolvimento das forças produtivas e o gênero humano.

É comum os livros de história das ideias apontarem as diferenças entre as duas primeiras posições: o projeto de criação de uma cultura proletária contrastando com o intento das vanguardas futuristas de renovação formal. Convém lembrar, contudo, que, apesar das críticas e disputas teóricas entre esses dois movimentos, o entusiasmo revolucionário aproximou diversas vezes os dois grupos, gerando colaboração e mútua influência.

Na Rússia, o entusiasmo pela revolução convivia com uma situação de penúria: boa parte do país não possuía energia elétrica e havia falta de papel e de outros materiais. Como "a necessidade é a mãe das invenções", os artistas 
Teatro, comunicação, pedagogia - Celso Frederico

ligados à proletkult, numa situação adversa, precisaram improvisar e lançar mão de meios para se comunicar com o público. A proposta de criar a nova cultura adaptada à nova sociedade foi tentada com grande entusiasmo pela iniciativa do teatro operário espalhado por todo o país. Foram utilizados trens de agitação e barcos de agitação para levar a arte ao povo².

$\mathrm{O}$ teatro de agitprop investia contra as formas tradicionais de se fazer arte e, ao mesmo tempo, dissolvia a própria instituição da arte como uma esfera separada da vida. Tudo ficava subordinado à eficácia política, à educação política, à urgência do momento, e não mais à busca do belo, como rezava a estética clássica.

A apropriação do fazer teatral por camadas marginalizadas da sociedade teve como consequência a modificação na própria concepção de teatro.

Antes de mais nada, as relações entre palco e plateia foram subvertidas: o público acompanhava a montagem do começo ao fim e opinava sobre tudo e, durante e após a apresentação, debatia criticamente a peça.

A linguagem teatral precisou modificar-se para adaptar-se à nova realidade. Os temas escolhidos e a fala dos personagens eram feitos a partir de pesquisas

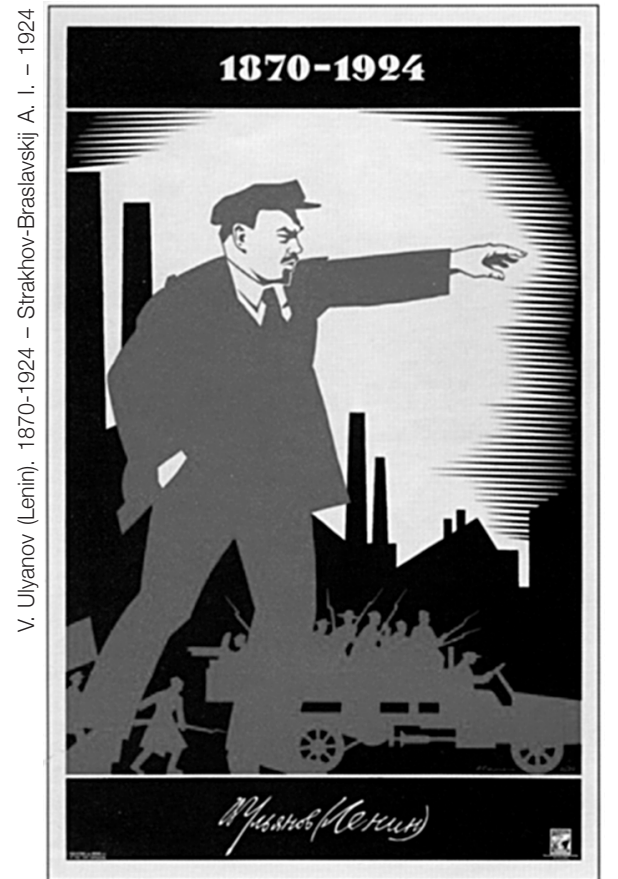

Litografia. Cartaz criado após a morte de Lenin. sobre a vida cotidiana dos trabalhadores. Tratava-se, assim, de um teatro colado aos fatos contemporâneos. E aí outra novidade: como inexistia uma dramaturgia nesses moldes pronta para ser utilizada, os grupos teatrais deixaram de lado os textos clássicos e partiram para a criação coletiva - o que representa mais uma inovação.

Ao objetivar a educação política e não a contemplação da própria arte teatral, o teatro operário lançou mão antropofagicamente de todas as referências possíveis: o folclore, o espetáculo de variedades, o circo, o teatro de cabaré e a própria arte de vanguarda.

A vanguarda, assim, encontrava-se com a proletkult, já que os dois movimentos estavam irmanados no processo revolucionário e na busca de uma nova arte. O trabalho gráfico da vanguarda, a produção de cartazes e pôsters, logo foi absorvido pelo teatro operário e apresentado nos palcos, seja como ilustração, seja como artifício para separar as cenas.

Finalmente, o entusiasmo vanguardista pelo cinema logo contagiou os partidários da proletkult.

Assim, duas correntes artísticas tão diferentes aproximaram-se movidas pelo apoio à revolução e pelo desejo de subverter a arte tradicional. Com a
2. Uma extensa documentação sobre o teatro operário encontra-se reunida nos quatro volumes da obra de BABLET, Denis. Le Théâtre d'Agit Prop: de 1917 à 1932 (O teatro de Agit Prop: de 1917 a 1932). Lausanne: La Cité/L'Âge d'homme, 4 v., ill., 1978. Os dois primeiros tratam da presença desse movimento na Rússia e os demais na Alemanha, França, Polônia e Estados Unidos. Sobre a efervescência cultural na Rússia e os debates entre as diversas tendências há extensa bibliografia. Dentre outros livros pode-se ler: os três volumes da obra de PALMIER, Jean-Michel. Lênin: a arte e a revolução. Lisboa: Moraes Editores, 1976; e MOSCATO, Antonio. Intelletualli e potere in URSS (1917-1956) (Intelectualiade e poder na Rússia [1917-1956]). Salento: Milella-Lecce, s.d. 
vitória da revolução, o teatro recebeu forte apoio do Estado. Mas esse apoio, se durante algum tempo fortaleceu nacionalmente o movimento teatral, de outro, acabou gerando um impasse que iria selar definitivamente a sorte daqueles grupos generosos e apaixonados por seu ofício. A presença tutelar do Estado contrariava o próprio espírito autogestionário e espontâneo daquela forma teatral. Por outro lado, o apoio estatal visava ao crescimento e profissionalização do teatro, fato que contrariava a pequena forma das peças e exigia um desempenho profissional aprimorado, nem sempre alcançado por aqueles atores improvisados ${ }^{3}$. Finalmente, a mudança de rumos após 1934 pôs fim à proletkult e aos demais movimentos culturais que foram enquadrados na estética oficial imposta pelo regime: o realismo socialista.

\section{O CONTEXTO ALEMÃO}

Diferentemente da Rússia, a Alemanha continuava sendo um país capitalista, mas vivendo igualmente uma efervescência política e cultural e a crença de estar às portas da revolução social.

Para explicar a peculiaridade alemã, os historiadores frequentemente assinalam a forma pela qual esse país se modernizou: a chamada via prussiana, que propiciou a transição ao capitalismo sem participação popular e sem democracia.

Esse componente estrutural da sociedade alemã permaneceu no início do século XX. Se o fim da Primeira Guerra Mundial, na Rússia, propiciou as condições para a revolução socialista, na Alemanha, contrariamente, assistiu-se a mais um episódio da via prussiana: a passagem negociada do Império para a República.

A República, portanto, não foi uma conquista a ser preservada, mas um regime que fez aflorar as contradições sociais que tiveram no nazismo o seu desfecho, atestando a fragilidade de uma República e de uma democracia que não havia sido conquistada por ninguém e que, portanto, ninguém se dispunha a defender. Este seria o pano de fundo que ajuda a entender a radicalização revolucionária e seus reflexos na vida cultural.

Amparado por um aguerrido movimento operário, artistas como Erwin Piscator procuraram encontrar uma arte que respondesse ao momento histórico. Entre as referências dessa busca estavam os jornais comunistas que abriam suas páginas para a colaboração de operários. Esses correspondentes operários enviavam informes narrando as condições de trabalho nas fábricas e a vida cotidiana dos trabalhadores. $\mathrm{O}$ estímulo à escrita fez com que esses informes, para muitos trabalhadores, marcassem o início de uma atividade que se desdobrou em reportagens e narrativas sobre a condição operária.

Dessa experiência, três coisas devem ser observadas:

3. Cf. GARCIA, Silvana, Teatro da militância. São Paulo: Perspectiva/Edusp, 1990. p. $43-44$
1) os operários, ao escreverem para o jornal, deixavam a condição de meros leitores. O fato de eles interferirem ativamente na elaboração subvertia o tradicional funcionamento do jornal - feito por profissionais e lido por consumidores; 
2) além disso, uma outra subversão ocorria. A imprensa, enfim, deixava de ser um órgão que apenas transmitia informações para tornar-se um órgão de comunicação feito com a colaboração de um leitor transformado em especialista em sua área de atuação. Essa busca da interatividade marcava a diferença tanto com a imprensa tradicional, controlada pelos seus proprietários, quanto com a imprensa soviética, cada vez mais controlada pelo Estado.

3) o fato de os operários tomarem a palavra - no jornal e em outras formas escritas e artísticas - fez com que muitos intelectuais vissem aí o nascimento de uma nova cultura que iria substituir à velha cultura burguesa.

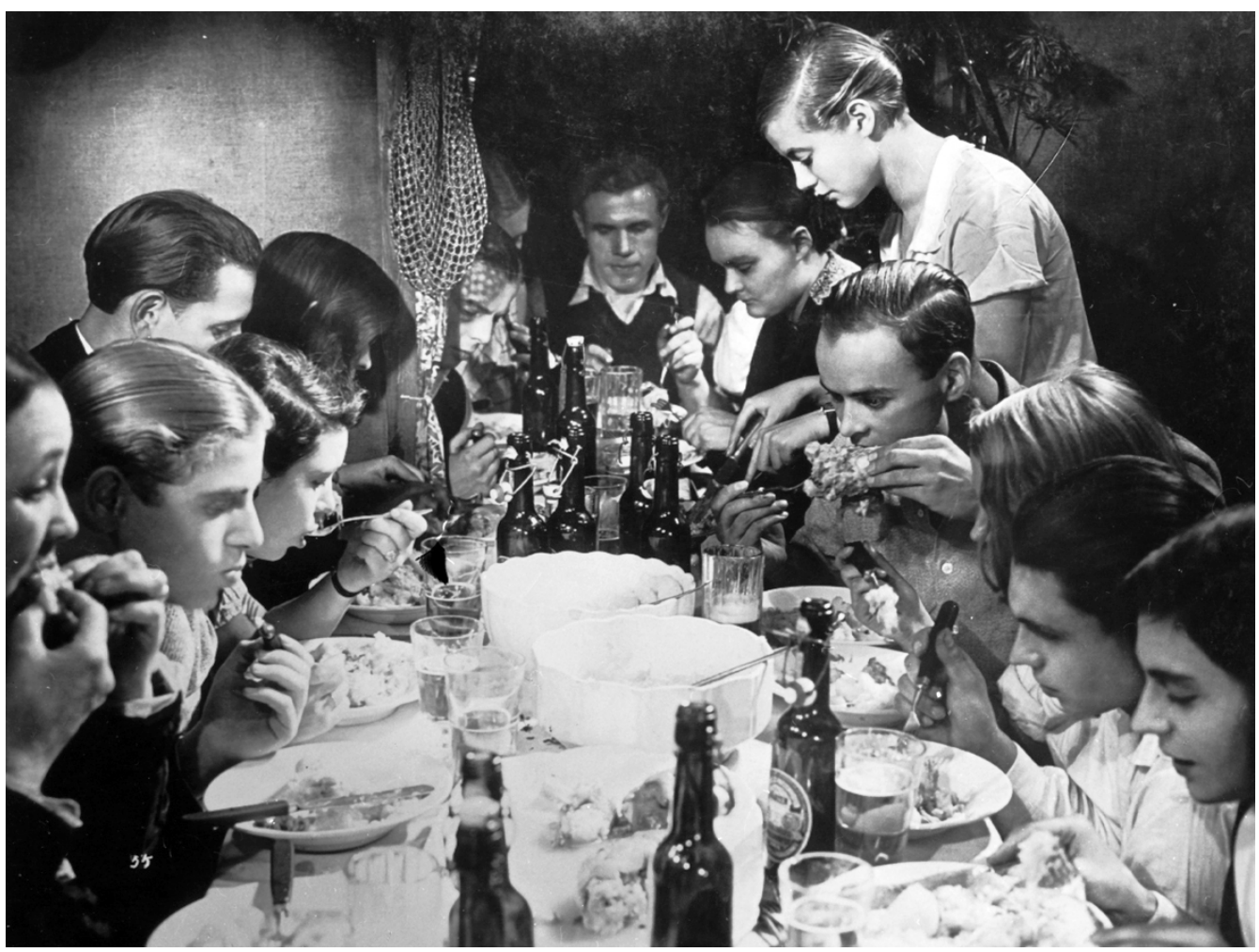

O filme Kuhle Wampe, dirigido por S. Dudow e rodado em 1931 ou 1932, com texto de Bertolt Brecht, enfoca o desemprego, e a a o se desenrola na Col nia de mesmo nome, fundada em 1913 na periferia de Berlim. Reflexão sobre o desemprego, as condições de vida da classe operária e suas formas de organização.

Piscator, partindo muitas vezes das informações fornecidas pelos correspondentes operários, procurava, através do teatro, dar uma representação cênica a esses relatos. Desse modo, a arte colocava-se diretamente a serviço da luta política. No limite, a concepção de Piscator, ao transformar o teatro numa assembleia permanente, implicava a própria supressão da arte enquanto prática específica: "Riscamos radicalmente a palavra arte do nosso programa: nossas peças eram apelos com os quais queríamos intervir no fato atual e fazer política".

O teatro, entendido como ação coletiva voltada à educação política, trouxe, evidentemente, uma radical transformação e diminuição do papel do autor. Este

4. PISCATOR, Erwin. Teatro político. Rio de Janeiro: Civilização Brasileira, 1968. p. 51. 
comunicação \& educação • Ano XV • Número 1 • jan/abr 2010

se torna secundário, um mero compilador de dados, um fazedor de reportagens sobre temas reais e atuais - e não mais um criador, como no sentido antigo.

Baseado nessa concepção, Piscator visava passar para o espectador informações políticas úteis. A representação teatral era acompanhada de leitura de jornais, quadros estatísticos, canções e filmes ilustrativos.

Em suma: Piscator procurou aplicar em seu país o modelo da proletkult:

1) revolução na estrutura interna do teatro: fim da ditadura do diretor através da criação coletiva;

2) revolução nas relações entre o palco e a plateia, através da participação ativa do público.

Com essa postura, Piscator aproximava-se dos vanguardistas no desprezo à arte burguesa, uma arte a ser desfrutada, degustada, apreciada, por um público seleto e de bom gosto. O que interessava, para todos eles, era a utilidade da arte, sua função de propaganda e de educação política, e não mais entreter o distinto público com dramas psicológicos.

Mas havia entre eles uma diferença: os vanguardistas, com Maiakóvski, afirmavam que sem forma revolucionária não há arte revolucionária e, por isso, criticavam os adeptos da proletkult de rechearem formas tradicionais com conteúdos revolucionários. Mas, paradoxalmente, a proletkult, ao buscar um novo conteúdo que substituísse a arte burguesa, acabou sendo levado a modificar as formas tradicionais de fazer teatro.

Outro ponto de diferenciação diz respeito aos contextos históricos e políticos.

$\mathrm{Na}$ Alemanha, o teatro político apoiava-se no movimento operário. Com a ascensão do nazismo, o movimento dos trabalhadores cai na clandestinidade, perde sua força e definha. A alternativa que sobrou para os artistas foi o chamado teatro invisível: os atores intervindo em cenas do cotidiano, sem que ninguém percebesse que se tratava de uma representação premeditada.

Na Rússia, como na Alemanha, a pretensão de criar através do teatro uma nova cultura acenava para a autodissolução da arte. Nos dois países, esses movimentos artísticos não resistiram à repressão estatal.

\section{PEÇAS DIDÁTICAS}

Ao contrário de Piscator, Brecht era um criador genial, que, pouco a pouco, foi decantando suas experiências até chegar à formulação madura do teatro épico. As influências de Piscator e também da vanguarda russa fizeram-no refletir sobre a necessidade de revolucionar a forma do teatro, indo além do maniqueísmo do teatro político.

A primeira forma encontrada foi a das chamadas peças didáticas - que consistiam basicamente em exercícios para os atores. A mais famosa delas, $O$ voo sobre o oceano - peça didática radiofônica para rapazes e moças, é, talvez, a mais conhecida delas. A façanha de Lindbergh, cruzando o oceano de avião, apresentava uma utilização inédita do rádio: é ele, o rádio, que narra a epopeia do herói. 
Teatro, comunicação, pedagogia - Celso Frederico

Nesse período, Piscator e Brecht, influenciados pelos construtivistas russos, estavam entusiasmados com o progresso técnico. O capitalismo parecia viver a crise agônica: as forças produtivas, as forças do progresso, atrofiadas por relações de produção arcaicas, eram o cenário que anunciava a revolução social. O socialismo, assim, era a própria promessa do progresso social; o avanço das forças produtivas insubordinando-se contra as relações de produção e sua expressão jurídica: a propriedade privada. Por isso, o teatro, nesse momento, foi invadido pela técnica: esteiras rolantes, palco giratório, introdução de filmes etc. Brecht, nos textos da época, utiliza-se constantemente de expressões como montagem, processo,

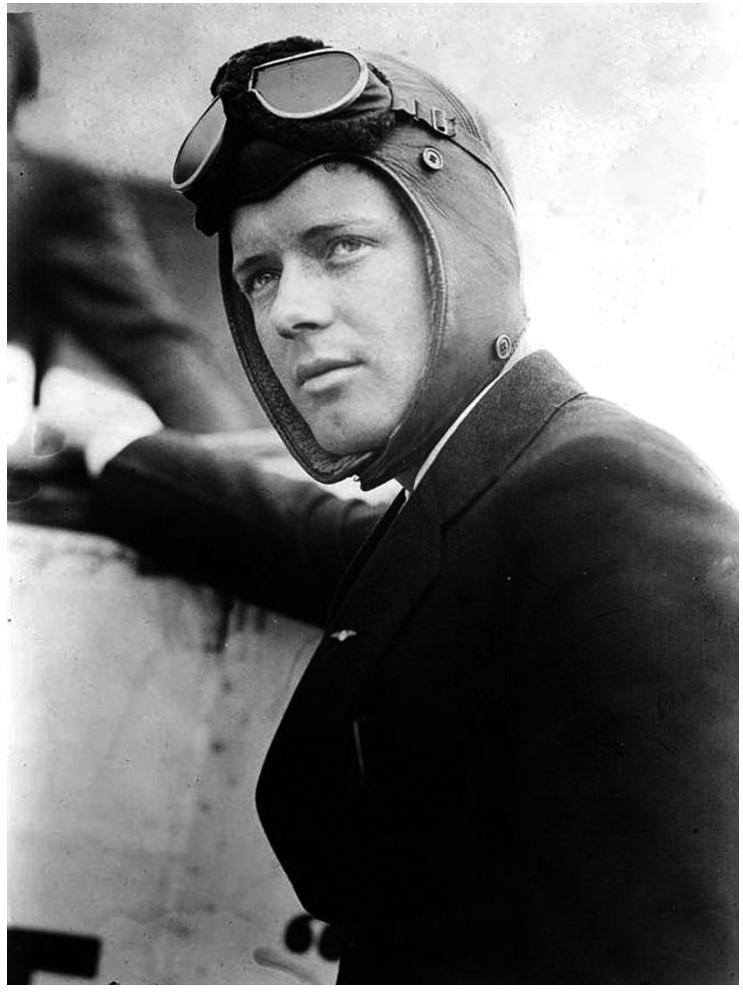

Charles Augustus Lindbergh, pioneiro da avia $0 . \frac{0}{0}$ norte-americana, famoso por ter feito o primeiro voo solitário transatl ntico sem escalas em avi o, em 1927. máquina, instrumento, experimento, ciência, produção etc.

Junto com a glorificação da técnica, emergia a necessidade de se fazer um teatro para o proletariado industrial, as massas. E aqui entra uma questão importante que estará presente em toda a obra de Brecht.

Tanto o romance clássico burguês como o teatro dramático concentravam-se no indivíduo e na introspecção psicológica. Contra essa tradição, Brecht pensa num teatro novo que prescindisse da psicologia do personagem, que enfatizasse a coletividade e que dissolvesse as situações nos processos. Portanto, os personagens deveriam ser reduzidos às funções sociais que eles exerciam.

A emergência das massas na vida política exigia novos personagens. A constatação de que o individualismo, produto da era liberal, era página virada para sempre na história, trouxe, para o artista, a necessidade de pôr em primeiro plano o sujeito coletivo emergente e mostrar que os personagens deviam ser vistos como agentes que cumprem determinada função social e, por isso, seriam elementos intercambiáveis. A identificaşão, propiciada pela empatia, deveria ceder lugar ao distanciamento, e a relação emocional do público (catarse), substituída pela reflexão.

Assim, para Brecht, a arte, ao contrário do realismo clássico, não deveria refletir a realidade como um dado fixo e imutável, mas mostrar que as personagens e as ações encenadas são como aparecem porque foram produzidas historicamente e, como tal, podem ser modificadas. A própria peça encenada 
comunicação \& educação • Ano XV • Número 1 • jan/abr 2010

5. Cf. ASCARELLI, Roberta. Comunicazioni di massa e movimento operaio (Comunicação de massa e movimento operário) Crítica marxista, Roma, n. 1, 1981.

6. Ibid
- acentuando o caráter fictício que recusa a imitação do real em nome da montagem constantemente fabricada e refabricada - é um modelo para a reflexão dos homens e um convite à participação social.

Numa de suas peças didáticas, Horácios e Curiácios, a plateia era convocada a remontar o enredo e opinar sobre como deveria ocorrer o seu desfecho. $\mathrm{O}$ teatro, portanto, não pretende mais representar uma história fechada: ele é concebido como uma montagem, uma criação coletiva, e não um fato consumado. O espectador era instado a sair da passividade e interferir nos rumos dos fatos encenados. Essa busca de uma comunicação interativa refletia a preocupação pedagógica e militante.

A nova arte, contemporânea do progresso técnico e do socialismo, procurava buscar o seu caminho contestando a velha arte burguesa.

É conhecido o interesse de Brecht pelo boxe. O aspecto gestual da competição esportiva foi repensado em sua teorização sobre o teatro. Impressionou-o, igualmente, a reação do público: os estádios estavam sempre repletos de espectadores que se divertiam, participavam e opinavam sobre o espetáculo, transformando-se, dizia Brecht, em especialistas no assunto, como, aliás, ocorre hoje com o futebol. Enquanto isso, o público cada vez mais reduzido das salas de teatro permanecia silencioso, contraído e passivo. Para conquistar uma audiência maior, o teatro precisava adotar uma nova postura, condizente com os tempos modernos, que pusesse fim à tradição elitista. Um teatro que instruísse e divertisse, que deixasse o público ao mesmo tempo relaxado e reflexivo - um teatro para fumantes.

Para entender esse momento de radicalismo em que Brecht escreveu as peças didáticas e a teoria do rádio, é preciso atentar para a conjuntura política. Após a expressiva vitória da esquerda nas eleições parlamentares de 1928, desenvolve-se uma intensa atividade cultural de cunho revolucionário. Essa atividade comprova a formação de um outro público produtor e consumidor de arte que exigia a renovação no modo de se fazer arte. A presença desse público manifestava-se na imprensa operária, na formação de um número impressionante de corais operários ligados à social-democracia, aos filmes feitos na Rússia e na Alemanha sobre a condição operária e na utilização do rádio pelos trabalhadores, formando comunidades de ouvintes. O sucesso do cinema junto ao grande público obrigou os partidos de esquerda a mudarem sua posição perante a sétima arte. A primeira tomada de posição oficial da social-democracia data de 1910, durante o congresso da juventude. O cinema, então, era visto como uma grave ameaça à formação ética e moral da juventude. Essa posição de recusa à sétima arte reaparece em 1912, no Congresso da Internacional em Zurich: resolve-se "boicotar a difusão do cinema entre os trabalhadores para evitar confusões entre a verdadeira cultura do movimento operário e as formas de divertimento propostas sub-repticiamente pela burguesia com o objetivo de adormecer os espíritos e confundir as mentes"5. Essa atitude regressiva foi mudando após a revolução russa e a difusão das ideias de Lênin sobre a eficácia propagandística do cinema. Em 1925, os comunistas alemães fundaram a firma Prometeus, para a criação e divulgação de filmes ${ }^{6}$. 
Teatro, comunicação, pedagogia - Celso Frederico

\section{TEMPOS DE EXÍLIO}

A ascensão do nazismo, colocando fim às experiências teatrais na Alemanha, levou o nosso autor a repensar o fazer teatral. A radicalidade das peças didáticas ficou para trás como um momento de experimentação importante, mas insustentável.

No exílio, Brecht foi amadurecendo sua concepção de teatro, porém, sem nunca abandonar a função pedagógica. Nas peças produzidas na República de Weimar, os personagens, quase sempre, eram reduzidos a meras funções sociais, seres desprovidos de subjetividade. Essa concepção extremamente objetivista, que faz do homem uma expressão direta das condições sociais, instigava Brecht a apontar e denunciar os mecanismos responsáveis pela produção dos indivíduos. Por isso, gostava de afirmar durante os ensaios e as representações: "Hoje vamos desmontar um homem como se desmonta um automóvel". Por outro lado, o extremado radicalismo do autor reduzia o papel da arte à utilidade. Renunciava, assim, naquele momento, a reivindicar qualquer especificidade à obra artística, fazendo do teatro um instrumento de intervenção direta na transformação social.

Depois, nas peças maduras, os personagens brechtianos progressivamente deixaram de ser meras funções sociais e adquiriram uma vida interior, uma subjetividade, como atestam diversas obras primas como Galileu Galilei, A mãe, $O$ círculo de giz caucasiano, entre outras.

Gerd Bornheim afirma que Brecht chegou então a aproximar-se da síntese entre uma estética do objeto e uma estética do sujeito por meio da revolução da forma, através de uma estética formal que substituiu a estética do objeto. Nisso, afirma o crítico, ele se parece com Picasso, que não pinta mais o objeto (uma maçã é para ser comida e não para ser pintada) nem o rosto de sua amada: ele pinta a pintura. A arte moderna, portanto, busca a pesquisa formal (metalinguagem). Ou nas palavras do autor: "A estética da pesquisa da linguagem independentemente do que se diga"7, da qual Brecht teria sido o precursor.

Aqui, peço licença para discordar deste grande crítico. Brecht sempre trabalhou tendo como pressuposto e objetivo o caráter pedagógico da arte. Como marxista, ele não poderia aceitar a tese da arte pela arte. As inovações formais, mesmo para um artista de vanguarda como ele, sempre estiveram a serviço da função pedagógica. Por isso, elas não devem evoluir a ponto de distanciar o público da arte e, assim, inviabilizar a função pedagógica.

Em seu diário de exílio, Brecht criticou Adorno e sua paixão pelos experimentos meramente formais. Numa das passagens, rememora com ironia:

Eisler tem razão de lembrar como era perigoso quando púnhamos em circulação inovações puramente técnicas, desligadas de qualquer função social. [...]

Quando zombei da declamação antinatural de textos pela escola de Schönberg, Adorno defendeu-a dizendo ter sido provocada pelo "desenvolvimento da música", que reclamava grandes e bruscos intervalos. Assim são considerações exclusivamente construcionais, quase matemáticas, e postulados de pura lógica na conjunção de material tonal que obrigam os músicos a rinchar como agonizantes cavalos de batalha... ${ }^{8}$.
7. BORNHEIM, Gerd. Brecht ainda hoje? Pandemonium Germanicum: revista de estudos germânicos. São Paulo, n. 4, p 68, 2000.

8. BRECHT, Bertolt. Diário de trabalho. Rio de Janeiro: Rocco, 2005. p. 101, v. II. 
comunicação \& educação • Ano XV • Número 1 • jan/abr 2010

\section{REFERÊNCIAS BIBLIOGRÁFICAS}

ASCARELLI, Roberta. Comunicazioni di massa e movimento operaio (Comunicação de massa e movimento operário). Crítica marxista, Roma, n. 1, 1981.

BABLET, Denis. Le Théâtre d'Agit Prop: de 1917 à 1932 (O teatro de Agit Prop: de 1917 a 1932). Lausanne: La Cité/L’Âge d'homme, 4 vol., ill.,1978.

BORNHEIM, Gerd. Brecht ainda hoje? In: Pandemonium Germanicum: revista de estudos germânicos, São Paulo, n. 4, 2000.

BRECHT, Bertolt. Diário de trabalho. Rio de Janeiro: Rocco, 2005. v. II.

GARCIA, Silvana. Teatro da militância. São Paulo: Perspectiva/Edusp, 1990.

MOSCATO, Antonio. Intelletualli e potere in URSS (1917-1956) (Intelectualidade e poder na Rússia [1917-1956]). Salento: Milella-Lecce, s.d.

PALMIER, Jean-Michel. Lênin: a arte e a revolução. Lisboa: Moraes Editores, 1976.

PISCATOR, Erwin. Teatro político. Rio de Janeiro: Civilização Brasileira, 1968.

\section{Endereços eletrônicos}

BRECHT, Bertolt. O rádio como aparato de comunicação. Discurso sobre a função do rádio. Estud. av. [on-line]. 2007, vol. 21, n. 60, p. 227-232. ISSN 0103-4014. Disponível em: <http://www.scielo.br/pdf/ea/v21n60/a18v2160.pdf>.

FREDERICO, Celso. Brecht e a "Teoria do radio". Estud. av. [on-line]. 2007, vol. 21, n. 60, p. 217-226. ISSN 0103-4014. Disponível em: <http://www.scielo.br/ pdf/ea/v21n60/a17v2160.pdf>. 